\title{
Proteomic Analysis of Larval Midgut from the Silkworm (Bombyx mori)
}

\section{Sai Zhang, Yunmin Xu, Qiang Fu, Ling Jia, Zhonghuai Xiang, and Ningjia He}

The Key Sericultural Laboratory of Agricultural Ministry, College of Biotechnology, Southwest University, Beibei, Chongqing 400715, China

Correspondence should be addressed to Ningjia He, hejia@swu.edu.cn

Received 3 September 2010; Revised 14 January 2011; Accepted 7 March 2011

Academic Editor: G. Pesole

Copyright $\odot 2011$ Sai Zhang et al. This is an open access article distributed under the Creative Commons Attribution License, which permits unrestricted use, distribution, and reproduction in any medium, provided the original work is properly cited.

The midgut is the major organ for food digestion, nutrient absorption and also a barrier for foreign substance. The 5th-instar larval stage of silkworm is very important for larval growth, development, and silk production. In the present study, we used 2-DE and matrix-assisted laser desorption/ionization time-of-flight mass spectrometry (MALDI-TOF-MS) to analyze the midgut proteins from the 5th-instar larvae as well as the midgut proteins under starvation condition. A total of 96 proteins were identified in this study; and among them, 69 proteins were observed in midgut for the first time. We also found that the silkworm larval midgut responded to starvation by producing a $10 \mathrm{kDa}$ heat shock protein and a diapause hormone precursor.

\section{Introduction}

Silkworm, Bombyx mori, is a domesticated insect for silk production. It is a lab-reared animal, and its relatively large size allows silkworm to be an important model in molecular genetics and in structural and functional genomics [1]. In addition, the silkworm also is a phytophagous insect and therefore a representative of lepidopteran pest insects.

The silkworm, as a holometabolous insect, has four remarkably different developmental stages: egg, larva, pupa, and moth. The larva is the only stage in which the animals feed and excrete in the whole life cycle. This stage, especially the 5th instar, is very important because the larvae have enough nutrient for growth, development, and silk production. The larval midgut is formed of an epithelial cell monolayer composed of columnar, goblet, and stem cells [2]. The columnar cells are mainly responsible for food digestion and nutrition absorption. Digestion is usually controlled by digestive enzymes and is dependent on their localization in gut [3]. The apical membrane of columnar cells is characterized by a well-developed brush border [4]. Goblet cells participate in the ionic regulation in gut, and the regenerative cells are responsible for renewing epithelial cells during metamorphosis [5].
Midgut is also a barrier to the foreign substances during food digestion. It has been found that some proteins such as lipase [6] and SP-2 [7] in midgut have antiviral activity against Bombyx mori nuclear polyhedrosis virus (BmNPV). Moreover, midgut has early been recognized as one of the important targets for insect control. One successful example is the transgenic crops that produce $B$. thuringiensis crystal $\delta$-endotoxins. These toxins bind to their receptors and then form a prepore oligomeric structure through which cell content leaking leads to the death of insect [8]. An alternative method for more specific control of insect is to silence the expression of genes using RNA interference (RNAi) through the midgut [9].

In order to understand the molecular mechanisms for nutrition digestion and midgut-derived defense, Yao et al. [10] and Kajiwara et al. [11] separately reported the proteomic analysis of the silkworm larval midgut. The former analysis was only performed on the 5th-instar day-3 silkworm larvae, and the later work focused on the midgut proteins from 5th-instar day-2 larvae. It is well known that biochemical metabolism is dramatically changed during the development of larval midgut in the 5th instar. In our current study, we are interested in ascertaining which proteins participate in midgut development in the penultimate instar 
larvae. Furthermore, when starvation is acted on animals, the animals will take violent responses to starvation by triggering emergent change in protein metabolism [12, 13]. These also can be revealed by proteomic analysis.

In the present study, we used 2-DE combined with MALDI-TOF-MS to analyze the midgut proteins of the 5thinstar larvae under normal and starvation conditions. As a result, 96 proteins were identified in this study and among them 69 proteins were observed for the first time. The results also indicated that the starved silkworm larval produced a $10 \mathrm{kDa}$ heat shock protein and a diapause hormone precursor in response to this disadvantage condition.

\section{Materials and Methods}

2.1. Insect and Protein Preparation. The silkworm strain $p 50$ (DaZao) used in this study was provided by the Institute of Sericulture and System Biology at the Southwest University of China. The larvae were reared on the fresh mulberry leaves at $25^{\circ} \mathrm{C}$ to the fifth instar day 3 . Then, the larvae were randomly divided into two groups. The larvae in group I still were reared on fresh mulberry leaves, while those in group II were starved until wandering stage (about $240 \mathrm{~h}$ ). Larvae randomly sampled from each group were dissected at 24-hour intervals, and the midguts were washed with $0.75 \% \mathrm{NaCl}$ solution and stored at $-20^{\circ} \mathrm{C}$. Larval midguts were ground to powder in liquid nitrogen with mortar and pestle. The proteins from silkworm midguts were extracted with $1 \mathrm{~mL}$ lysis buffer ( $8 \mathrm{M}$ urea, 4\% (m/v) 3[(3-cholamidopropyl) dimethylammonio]-1-propane sulphonate (CHAPS, Sangon, shanghai, China), and $4 \%(\mathrm{~m} / \mathrm{v})$ dithiothreitol (DDT, $\mathrm{BBI}$, Canada) ) at $4^{\circ} \mathrm{C}$ for $40 \mathrm{~min}$. After centrifuging twice at $12,000 \mathrm{~g}$ for $15 \mathrm{~min}$, the supernatants were collected for proteomics analysis. The concentration of proteins was measured by Bradford kit as described in manufacturer's instructions (TIANGEN, Beijing, China).

2.2. Two-Dimensional Gel Electrophoresis. The midgut proteins were separated by two-dimensional electrophoresis according to the manufacturer's instructions (GE Healthcare, USA). Briefly, proteins were dissolved in rehydration solution (8 M urea, 2\% CHAPS, $0.28 \%$ DDT, and 1\% IPG buffer $\mathrm{pH} 3-10)$. The protein solution was loaded onto an immobilized PH gradients strip (IPG strip, $18 \mathrm{~cm}$, line, $\mathrm{pH}$ 3-10, GE Healthcare, Sweden). Isoelectric focusing (IEF) was performed as follows: $50 \mathrm{~V}$ for $12 \mathrm{~h}, 100 \mathrm{~V}$ for $1 \mathrm{~h}, 200 \mathrm{~V}$ for $1 \mathrm{~h}, 500 \mathrm{~V}$ for $30 \mathrm{~min}, 1000 \mathrm{~V}$ for $30 \mathrm{~min}, 3000 \mathrm{~V}$ for $30 \mathrm{~min}$, and $8000 \mathrm{~V}$ for a total of $70000 \mathrm{Vhr}$ (voltage multiplied by hours). The current did not exceed $50 \mathrm{~mA}$ per strip. After IEF, the strips were equilibrated in equilibration buffer I $(50 \mathrm{mM}$ Tris- $\mathrm{HCl}, \mathrm{pH} 8.8,6 \mathrm{~mol} / \mathrm{L}$ urea, $30 \%$ glycerol, $2 \%$ SDS, and 1\% DTT) for $15 \mathrm{~min}$ and then in buffer II (replaced 1\% DTT with 2.5\% iodacetamide) for another $15 \mathrm{~min}$. The equilibrated gel strip was loaded onto a $12.5 \%$ SDS-polyacrylamide gel. Electrophoresis was carried out in an Ettan DALTsix vertical electrophoresis system (Amersham Biosciences, Sweden) at $10 \mathrm{~mA}$ per gel for approximately $1 \mathrm{~h}$, and then switched to $40 \mathrm{~mA}$ per gel until the bromophenol blue reached the bottom of the gel. Protein was visualized by silver staining.

2.3. Gel Image Analysis. The resultant 2D gels were scanned by Image Scanner III (GE Healthcare, USA) with LabScan 6.0 software (GE Healthcare, USA) at an optical resolution of $300 \mathrm{dpi}$. The scanned gels were analyzed using the ImageMaster 2D platinum 6.0 (GE Healthcare, USA) software supplied by the manufacturer, and the parameters for spots detecting were set to smooth: 2-5, minarea: $30-50$, and saliency: 5-15.

2.4. In-Gel Digestion and MALDI-TOF-MS Analysis. The protein spots excised from the gels were cut into small pieces (about $1 \mathrm{~mm}^{3}$ ) and transferred into $0.5 \mathrm{~mL}$ Eppendorf tubes. In-gel digestion was carried out according to what was previously described in [14]. In brief, $100 \mu \mathrm{L}$ of destaining solution $\left(15 \mathrm{mmol} / \mathrm{L} \mathrm{K}_{3}\left[\mathrm{Fe}(\mathrm{CN})_{6}\right], 50 \mathrm{mmol} / \mathrm{L} \mathrm{Na}_{2} \mathrm{~S}_{2} \mathrm{O}_{3}\right)$ was added to each tube for $10 \mathrm{~min}$ destaining. Then, the gel pieces were washed with $\mathrm{ddH}_{2} \mathrm{O}$ for $15 \mathrm{~min}$ for three times. The gel pieces were dehydrated with $100 \mu \mathrm{L}$ ACN until the gel pieces turned opaque white. The ACN was discarded after centrifugation. The gel pieces were dried at room temperature for more than $40 \mathrm{~min}$. Fifty microgram trypsin $(10 \mathrm{mg} / \mathrm{mL}$ in $25 \mathrm{mM} \mathrm{NH}_{4} \mathrm{HCO}_{3}, \mathrm{PH}$ 8.0, Sigma, USA) was added to each tube and the incubation was carried out at $37^{\circ} \mathrm{C}$ for $16-$ $20 \mathrm{~h}$. The tryptic peptides were extracted twice with $30 \mu \mathrm{L}$ $50 \%$ ACN/5\% trifluoroacetic acid (TFA, Sigma, USA). The supernatants were pooled and dried in a Centrivap Cold Trap (LABCONCO, USA). Prior to mass spectrum analysis, the peptides were redissolved in $3 \mu \mathrm{L}$ of $50 \% \mathrm{ACN} / 0.5 \%$ TFA and equally mixed with saturated $\alpha$-cyano-4-hydroxycinamic acid (CHCA, Sigma, USA). The mass spectra of the peptides were recorded on a Voyager DE PRO MALDI-TOF-MS (Applied Biosystems, USA). The database used in this analysis contained two parts of protein sequence: 6642 silkworm protein sequences downloaded from NCBI (http://www .ncbi.nlm.nih.gov/) with keyword of Bombyx and 14623 sequences generated by the annotation of silkworm genomic sequences (http://silkworm.swu.edu.cn/silkdb/doc/download .html). The analysis of mass spectra and the process of protein identification were carried out according to a previous study [14].

2.5. RNA Extraction and Real-Time PCR. Total RNA was extracted from the midgut tissues in two groups using Trizol reagent (Invitrogen, USA). The RNA samples were dissolved in RNase-free water, and the concentrations were measured using spectrophotometer (Amersham Biosciences, Sweden). According to the protocol, $3 \mu \mathrm{g}$ of total RNAs were used to synthesize the first-strand cDNA in $25 \mu \mathrm{L}$ of reverse transcription PCR system with AMV Reverse Transcriptase (Promega, USA). For real-time PCR, the primers designed for $10 \mathrm{kDa}$ small heat shock protein gene were $5^{\prime}$-GTTCCTCTTCTGGACCGTG-3' (forward) and 5'-GACCGACCGCTACTACTTCT-3' (reverse), and for diapause hormone precursor gene were 5'-GGAAATGTACCAACCTGACCC$3^{\prime}$ (forward) and 5'-AACGCTTCTGGCAACCCTAT-3' 


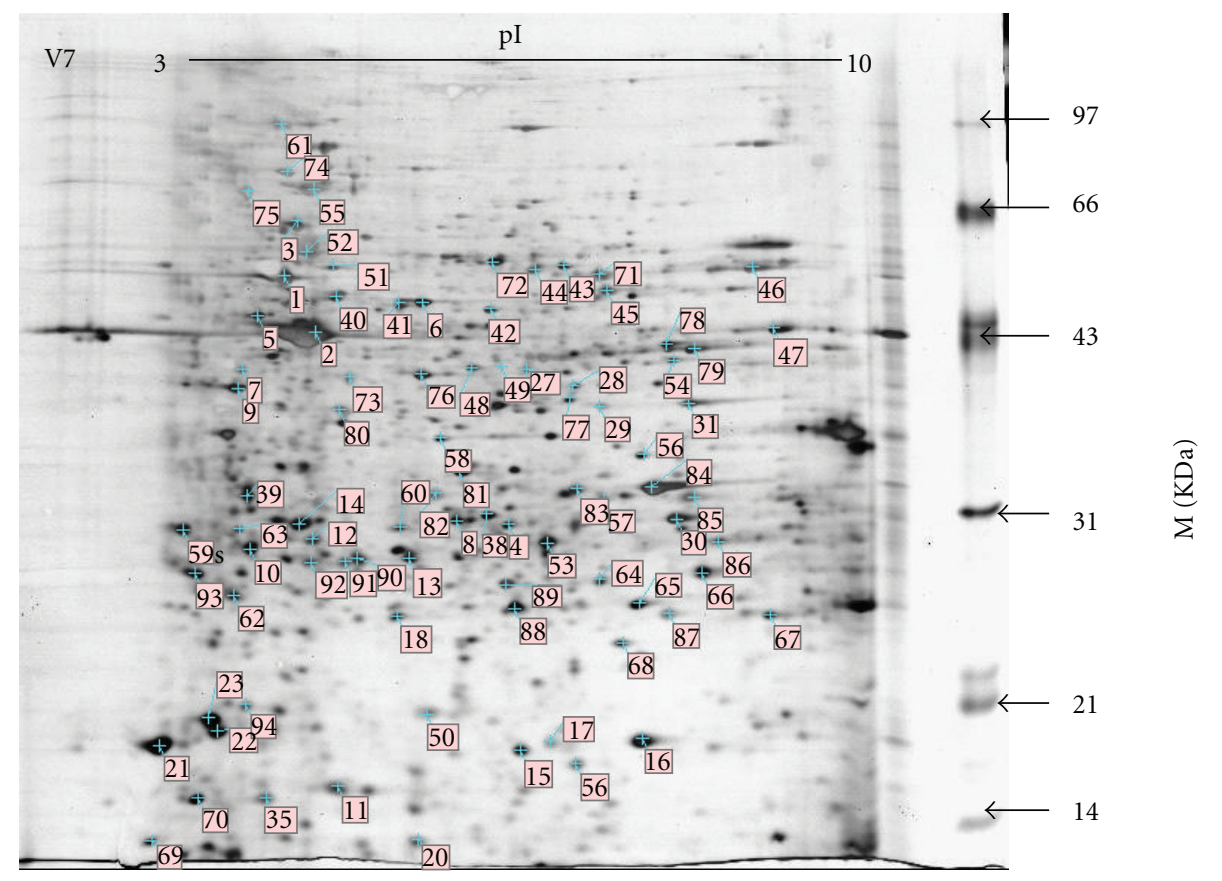

FIgURE 1: The 2-DE profile of midgut proteins at the fifth-instar day 7 larvae. A total of $300 \mu \mathrm{g}$ protein from midgut was applied onto a pH 3-10 Immobiline dryStrip $(18 \mathrm{~cm})$ for the first-dimensional electrophoresis and then separated by $12.5 \%$ SDS-PAGE. The 2-DE gels were stained by silver. Proteins identified in this study are indicated, and the numbers corresponded to those are in Table 1.

(reverse). Real-time PCR was performed in triplicate for each gene of interest in $20 \mu \mathrm{L}$ reactions with reverse transcription product, $2 \times$ PCR buffer, $50 \times$ ROX Reference Dye, $100 \mathrm{nM}$ of each of the forward and reverse primer, and RNase free ddH2O. The PCR reaction was performed on an ABI Prism 7000 Sequence Detection System (Applied Biosystems) using the following program: initial denaturation at $95^{\circ} \mathrm{C}$ for $10 \mathrm{sec}$ and 40 cycles of $95^{\circ} \mathrm{C}$ for $5 \mathrm{sec} 60^{\circ} \mathrm{C}$ for $31 \mathrm{sec}$. $\beta$-actin 3 was used as inner control.

\section{Results}

3.1. 2-DE Profiles of Silkworm Larval Midgut Proteins. The silkworm midgut proteins were extracted from the fifthinstar day-4 (V4) to day-8 (V8) feeding larvae and from the fifth-instar day-4 (V4N) to day-13 (V13N) nonfeeding larvae. A total of 15 extractions were separated by $2 \mathrm{D}$ technology, as shown in Supplemental Data 1 and 2 in Supplemental Material available at doi:10.1155/2011/876064. The protein spots were then detected using ImageMaster 2D platinum 6.0 software. On the gels V4 to V8, 439, 461, 498, 606, and 620 protein spots were detected, respectively. And on the gels V4N to V13N, 420, 455, 500, 610, 630, 635, 643, 640,660 , and 684 protein spots were detected, respectively. The number of protein spots increased gradually with the development of larvae in two groups. As shown in Figure 1, the protein spots on the V7 gel were marked by number and further analyzed by a Voyager DE PRO MALDI-TOFMS. After being searched by GPMAW software, proteins with more than five matched peptides and the coverage of peptides larger than $20 \%$ were accepted. The results were summarized in Table 1. A total of 96 proteins were identified. Among them, protein spots no. 95 and 96 were only found in nonfeeding midgut. When compared to the data obtained from the previous studies $[10,11,15,16], 69$ proteins, accounting for $71 \%$ of all proteins, were found at the first time in our present study. Based on the molecular function and GO annotation (see below), these 96 proteins were classified into 12 categories including: (1) eight are for nutrition storage, (2) three for cell growth, (3) sixteen for protein metabolism, (4) three for carbohydrate metabolism, (5) nine for lipid metabolism, (6) eighteen for energy metabolism, (7) three are immune-related proteins, (8) two are antioxidation proteins, (9) eleven are muscle-related proteins, (10) five are for hormone metabolism, (11) sixteen for other functions, and (12) two are unannotated proteins. The identified proteins have been submitted to http://silkworm .swu.edu.cn/cgi-bin/wego/index.pl for GO (gene ontology) annotation. As shown in Figure 2, 96 proteins were classified into three groups including cellular component, molecular function containing binding, catalytic, transporter, electron carrier, and antioxidant, and biological processes involved in metabolism, cellular process, and biological regulation.

3.2. Changes in Protein Pattern in the Development of the Midguts of Normal-Feeding Silkworm Larvae. As shown in Figure 1 and Supplemental data 1, the composition of the silkworm midgut proteins was different from V4 to V8. The number of protein spots, especially those ranging in size from $30 \mathrm{kDa}$ to $90 \mathrm{kDa}$ at higher pI region, gradually increased with the growth of larvae. Table 1 showed that the abundances of 64 midgut proteins were different from V4 


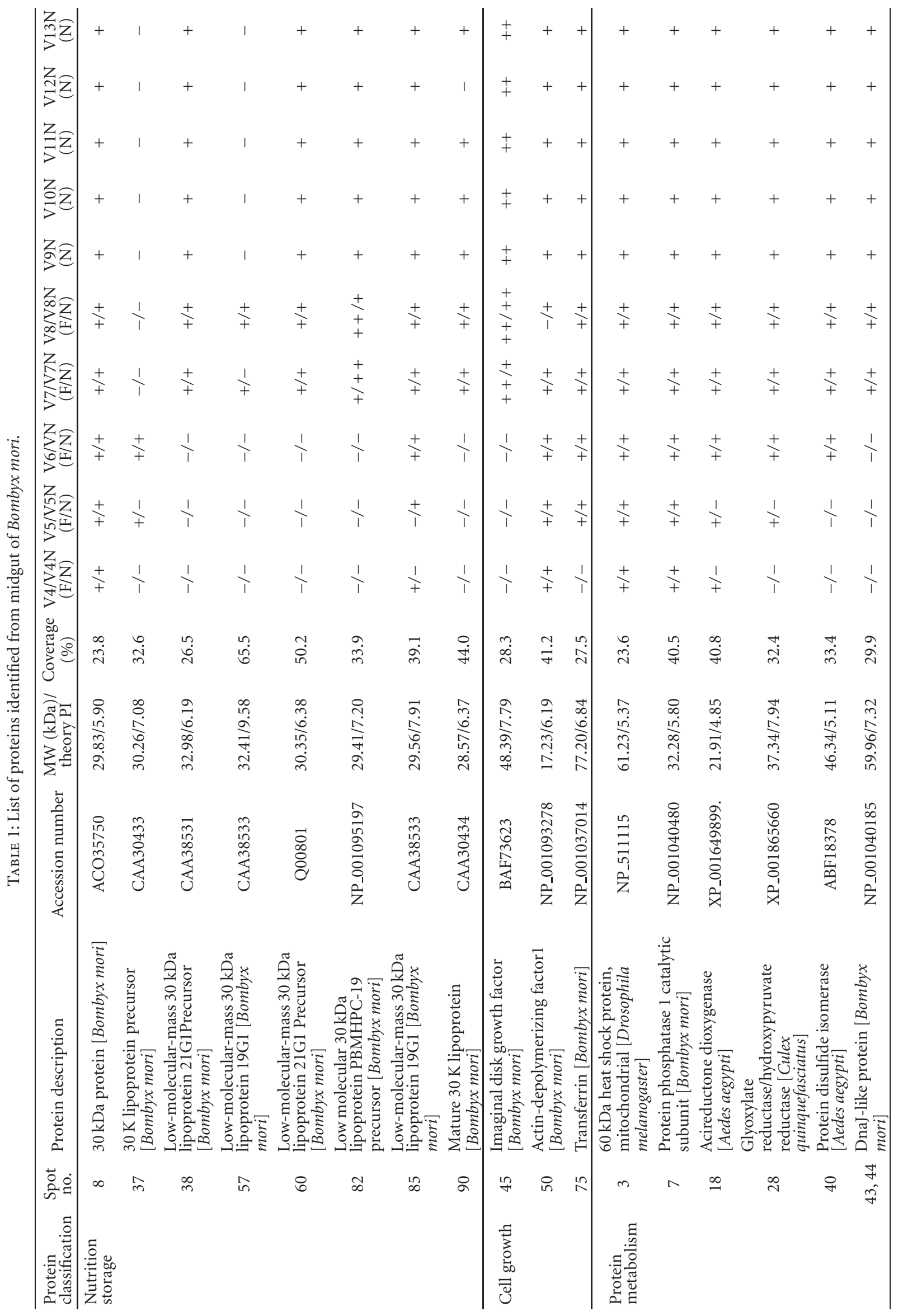




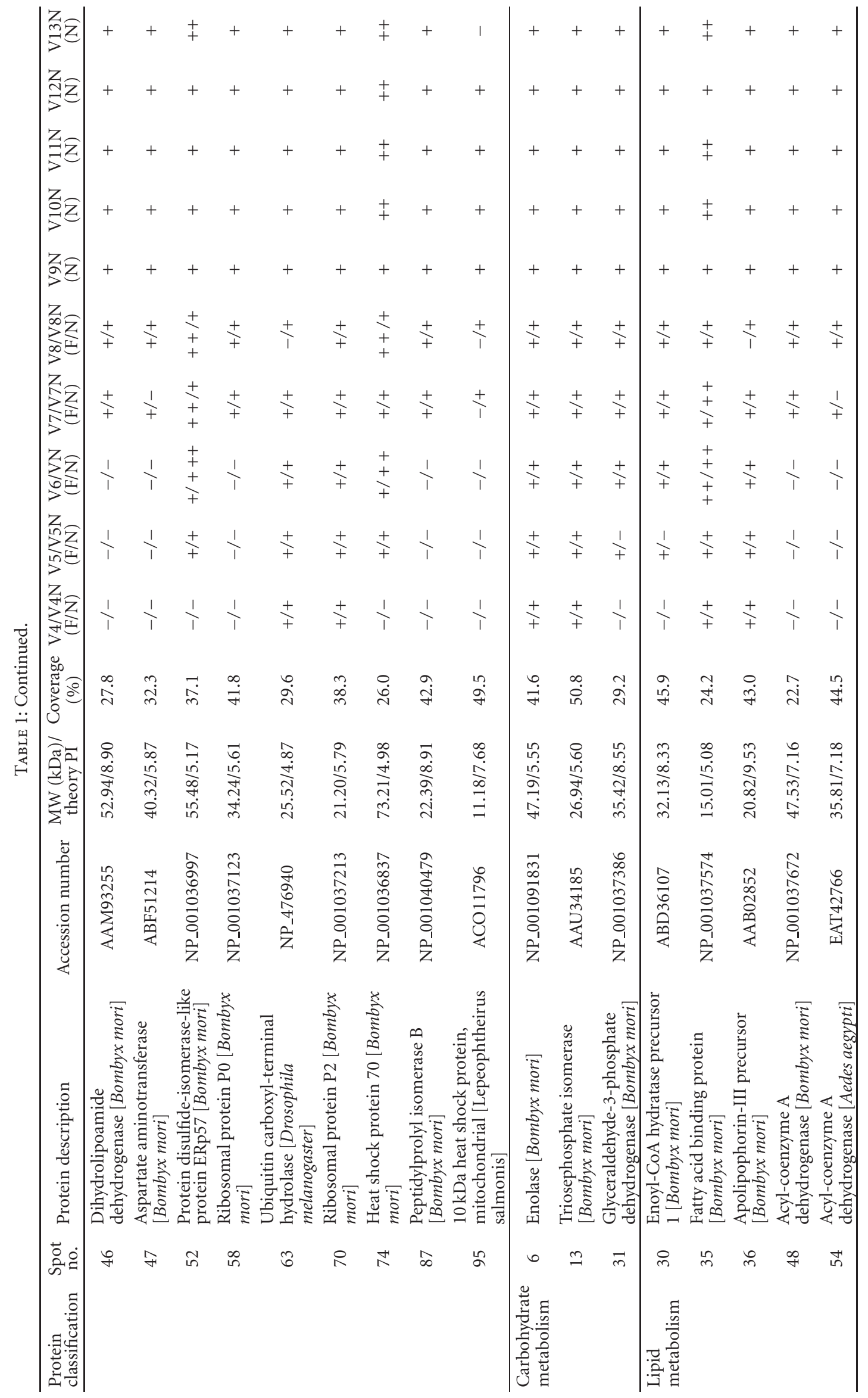




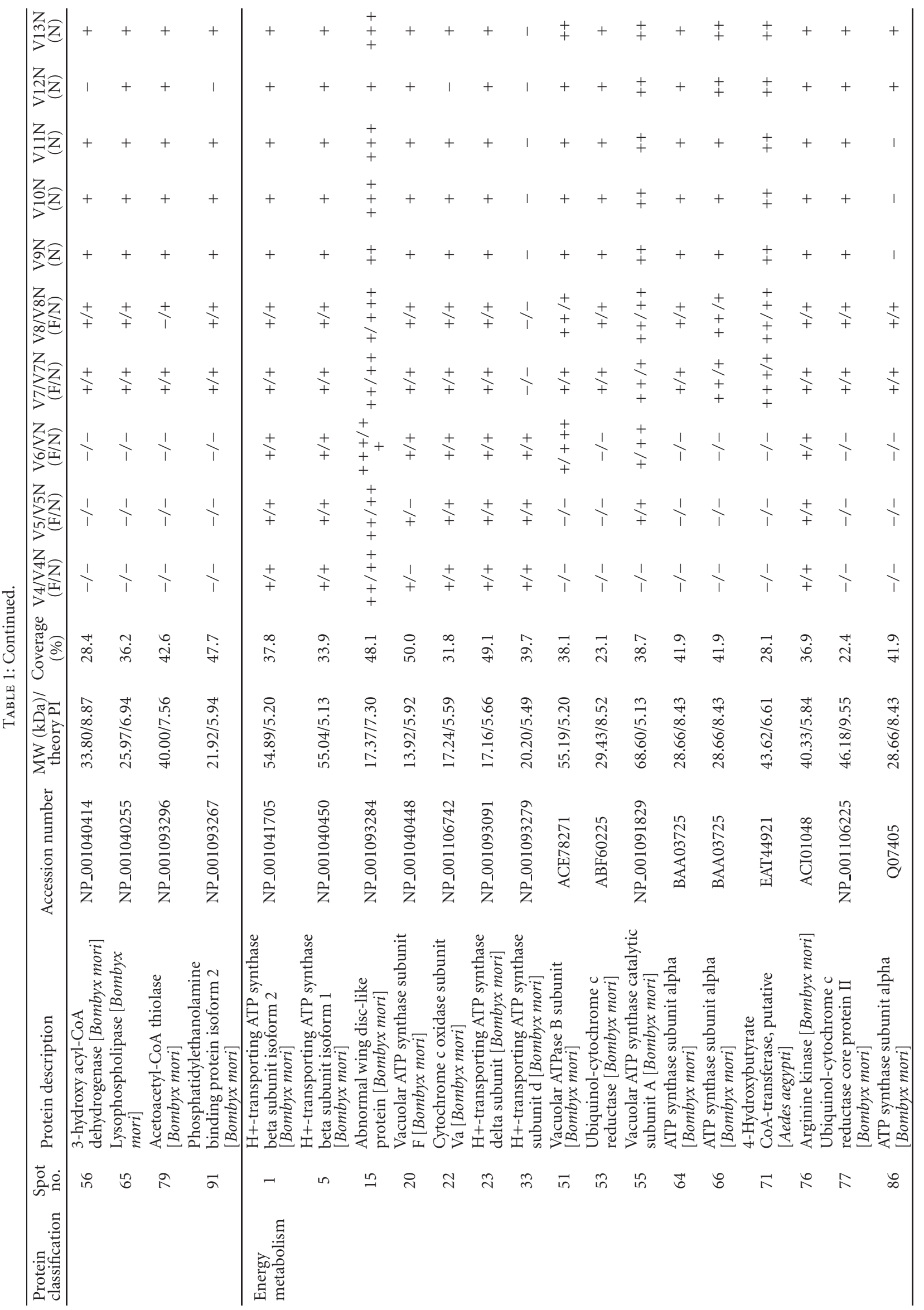




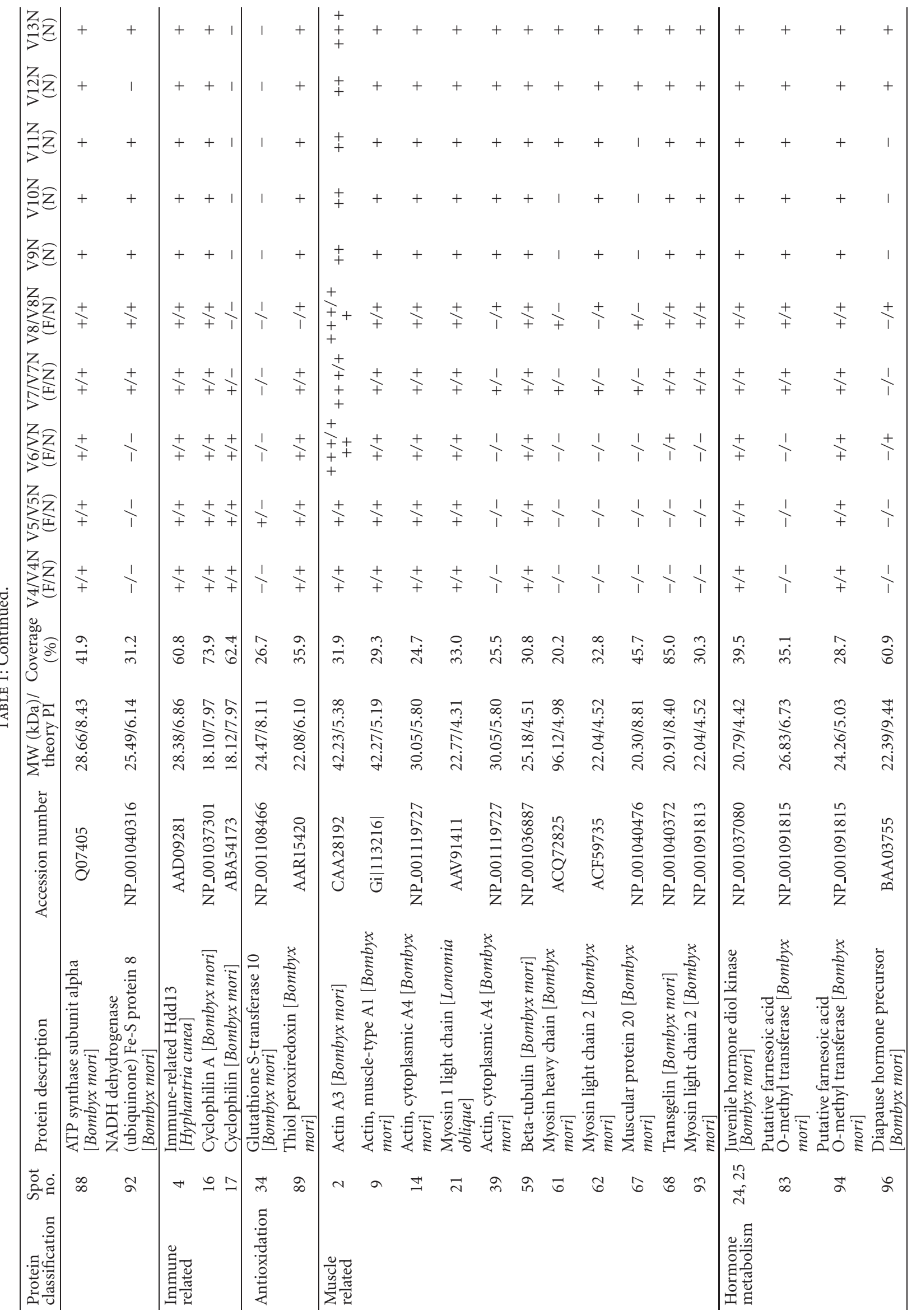




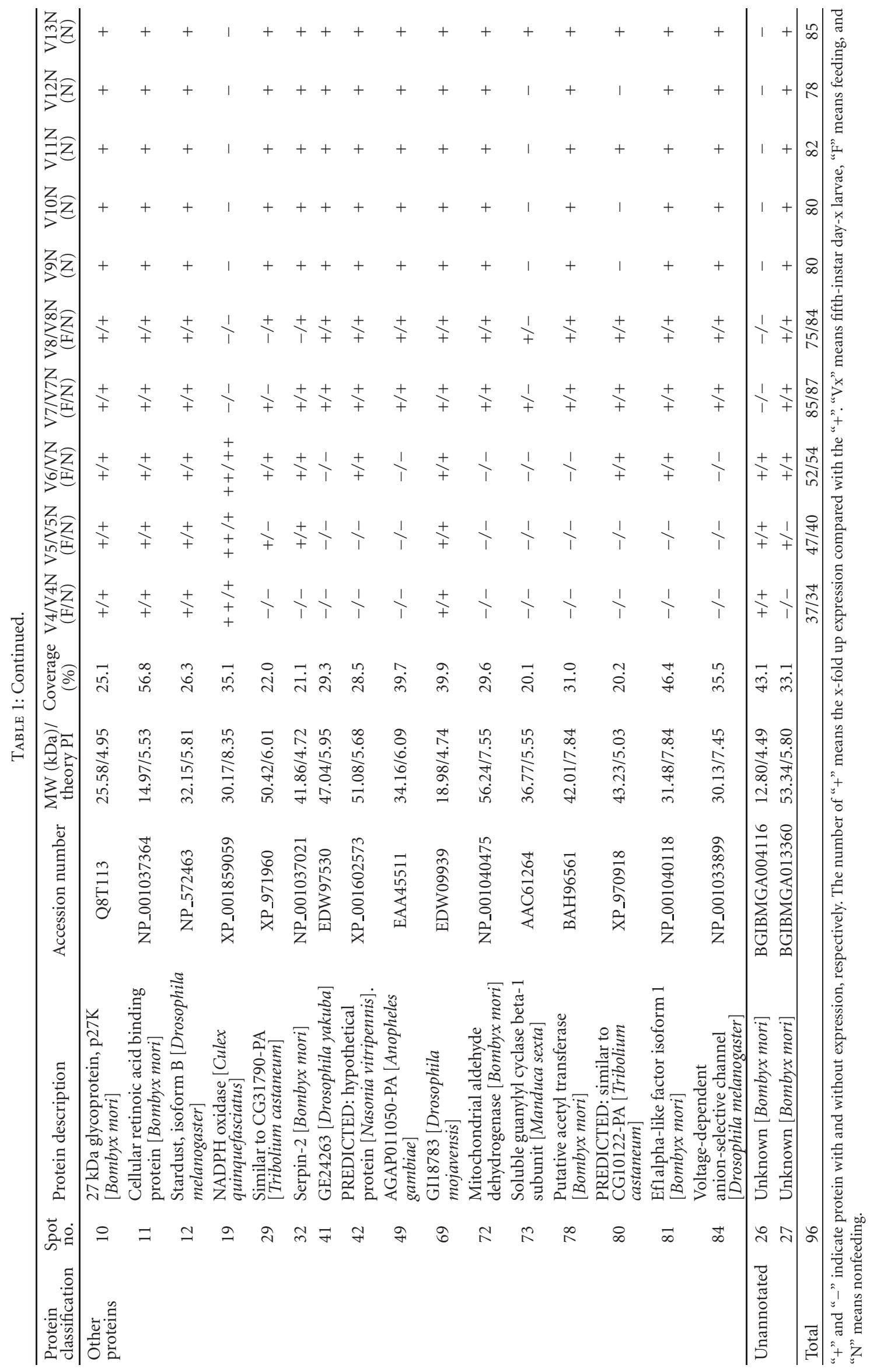




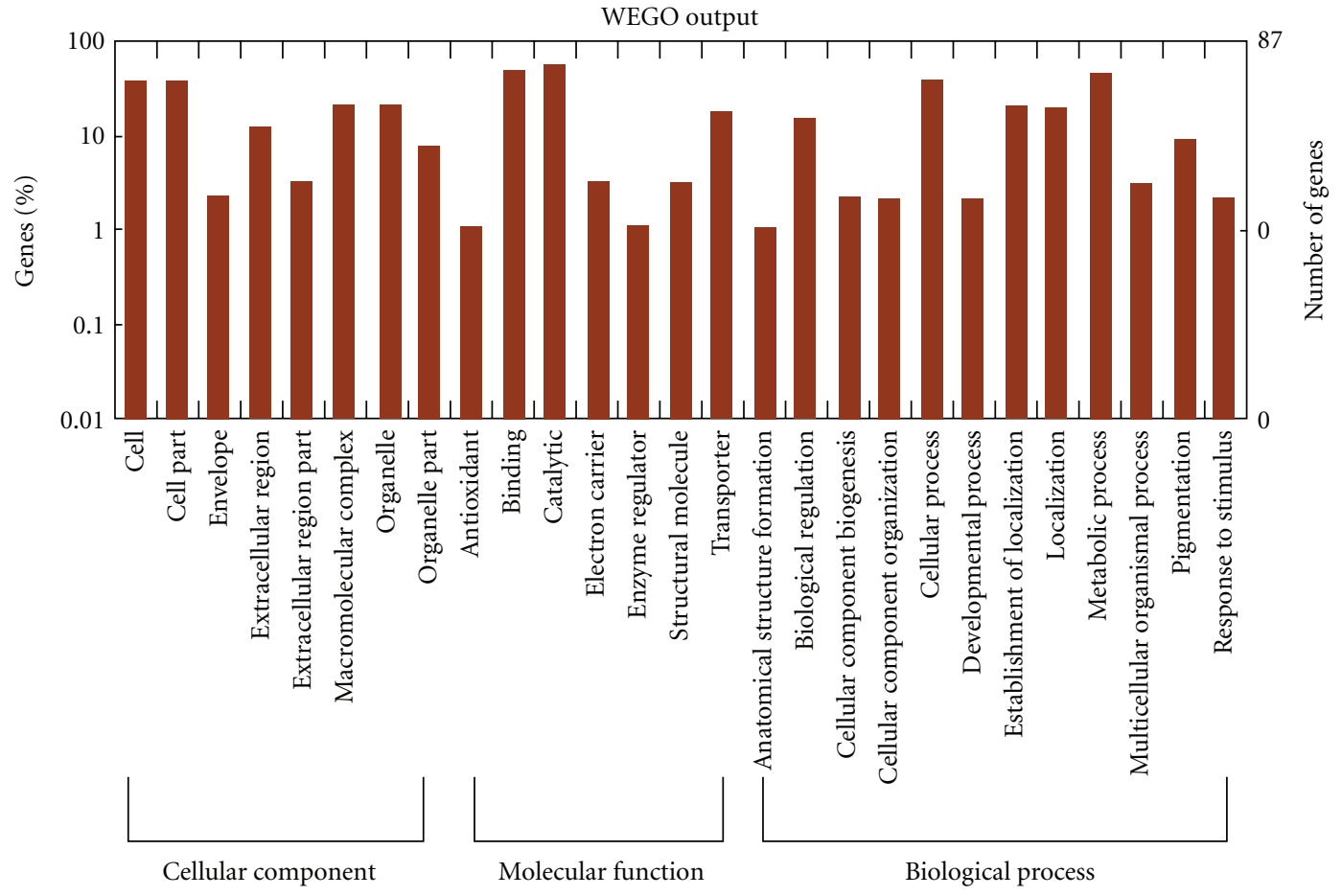

FIgURE 2: GO categories of the identified proteins by Wego software.

to V8, mainly including those involved in nutrition storage, protein/lipid/energy metabolism, and muscle-related proteins. Most prominent among them were thirteen proteins with more than two-fold differential expression. Two spots corresponding to a juvenile hormone diol kinase (JHDK) and a fatty-acid-binding protein were present from V4 to V8, and displayed the highest expression level in V6 (Figures $3(\mathrm{a})$ and $3(\mathrm{~b}))$. An abnormal wing disc-like protein had a peak in V7 (Figure 3(c)). From Figures 3(d) to 3(i), one can see that ten proteins among which two were lowmolecular-mass $30 \mathrm{kDa}$ lipoproteins 19G1 and PBMHPC19 precursor, three were ATP synthase subunits, and five were, respectively, protein disulfide-isomerase-like protein (PDI) ERp57, enolase, arginine kinase, Enoyl-CoA hydratase precursor 1 , and actin were expressed at relatively higher levels in V8. From Table 1, we also found that 6 proteins (spot no. $17,19,26,33,34$, and 37 ), a $30 \mathrm{~K}$ lipoprotein precursor, an H+-transporting ATP synthase subunit, a cyclophilin, a glutathione S-transferase10, a NADPH oxidase, and an unknown protein, were barely detectable before metamorphosis in feeding larvae.

3.3. Midgut Proteins in Response to Starvation. After being fed with mulberry leaves for three days, a part of these fed silkworm larvae were separated for starvation treatment. The starved larvae survived for 10 days. Most of them were dead during starvation. At the day 13 (V13N), a few larvae struggled to pupate. The midguts were carefully collected at 24-hour intervals from the starved larvae until day $13(\mathrm{~V} 13 \mathrm{~N})$. We subsequently investigated these 10 protein samples from V4N to V13N by 2D electrophoresis coupled with MALDI-TOF MS. Supplemental Data 2 showed that the protein profiles of $\mathrm{V} 4 \mathrm{~N}$ and $\mathrm{V} 5 \mathrm{~N}$ were quite similar to each other, and the number of the protein spots on both gels was decreased as starvation time increased, compared to those in V4 and V5. However, the spot number was dramaticly increased at $\mathrm{V} 6 \mathrm{~N}$ compared to that in V5N. On the V6N to $\mathrm{V} 12 \mathrm{~N}$ gels, the numbers of protein spots were also increased and varied from 610 to 660 . The protein distribution pattern of $\mathrm{V} 6 \mathrm{~N}$ to $\mathrm{V} 12 \mathrm{~N}$ resembled those of V5 to V8, suggesting that the starved larvae might keep their midgut intact and functional for a period of time. It is also important to note that the spot number was increased at $\mathrm{V} 13 \mathrm{~N}$, up to 684 , presumably coincident with the striking alteration of starved larvae at that stage.

The proteins identified in starved larval midgut were summarized in Table 1. As shown in Table 1, over $50 \%$ of identified proteins in nonfeeding silkworm larvae had a similar variation trend to that in normal feeding ones. On the contrary, 17 proteins delay their presentation compared with those in feeding group. Moreover, nine proteins (spot no. 29, $32,36,39,50,62,63,79$, and 89) still present in nonfeeding larvae were undetectable before metamorphosis in feeding larvae; as a representative data, the expression pattern of actin-depolymerizing factor 1 was shown in Figure $4(\mathrm{~g})$.

In Figures 4(a) and 4(b), a $10 \mathrm{kDa}$ heat shock protein and a diapause hormone precursor were only detected in the nonfeeding groups. Real-time PCR was carried out to reveal changing expression patterns of two genes encoding the $10 \mathrm{kDa}$ heat shock protein and diapauses hormone precursor. The data showed that this small heat shock protein gene 
(a)

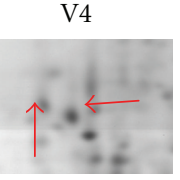

(b)

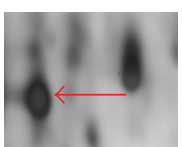

(c)

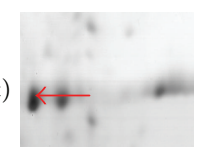

(d)

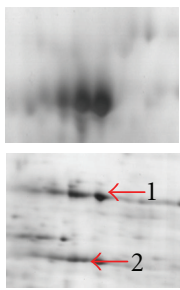

(f)

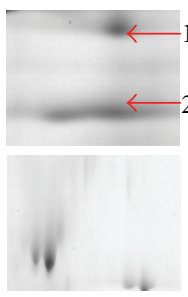

(h)

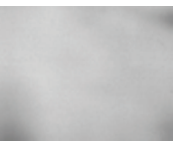

(i)

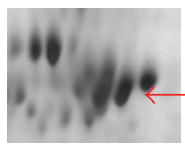

V5
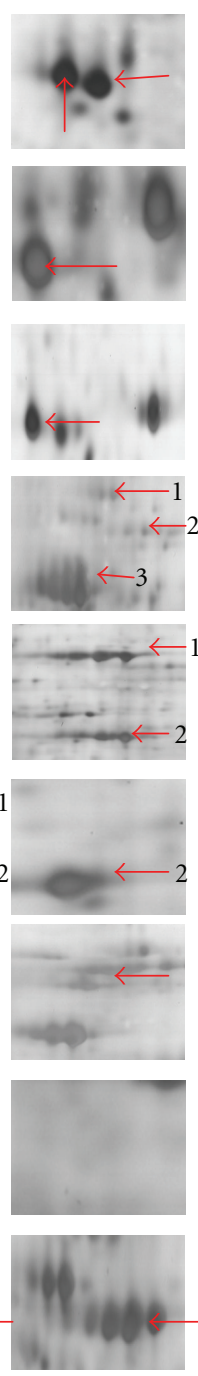

V6
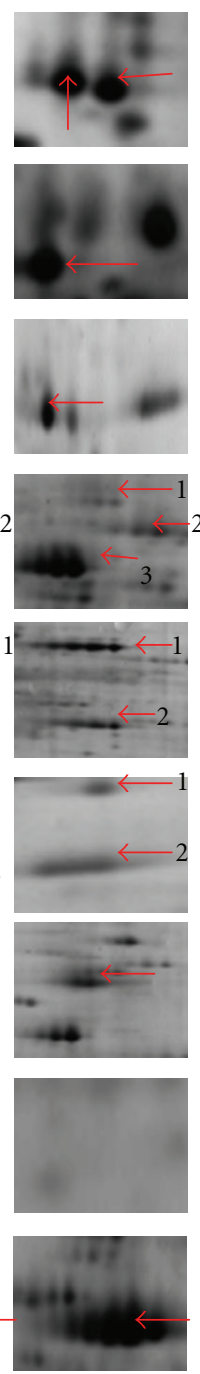

V7
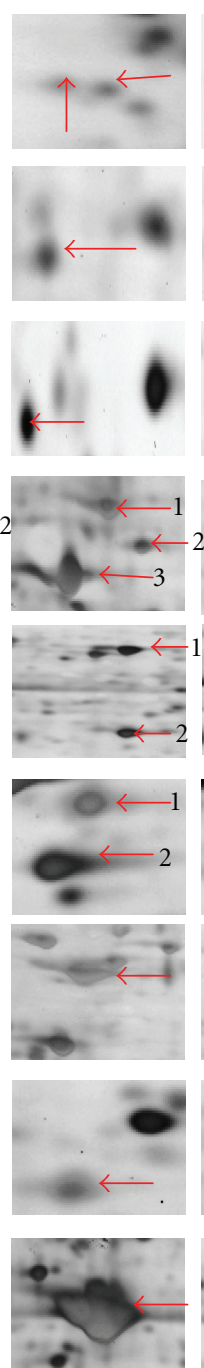

V8
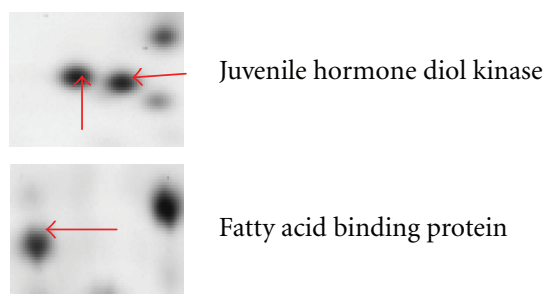

Fatty acid binding protein

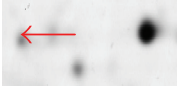

Abnormal wing disc-like protein

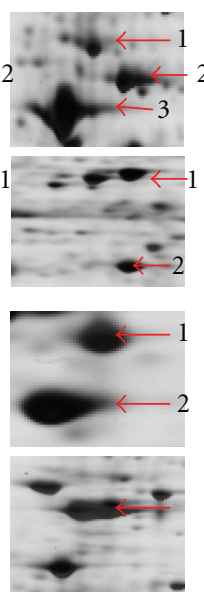

Protein disulfide-isomerase like protein ERp57

$2 \mathrm{H}^{+}$transporting ATP synthase $\beta$ subunit isoform 2

Vacuolar ATPase B subunit

Enolase

Arginine kinase

Low-molecular-mass $30 \mathrm{kDa}$ lipoprotein

19G1

Enoyl-CoA hydratase precursor 1

Vacuolar ATP synthase

catalytic subunit A

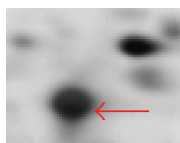

Low-molecular-mass $30 \mathrm{kDa}$ lipoprotein

PBMHPC-19 precursor

FIGURE 3: The partial enlargement of midgut proteins changed with development in normal feeding silkworm. Red arrows pointed out the target proteins and their names were displayed at right. Vx means fifth-instar day-x larvae.

was expressed in the normal feeding and nonfeeding larvae, but its peak signal can be detected after spending nine days in starvation (Supplementary Data 3A). As shown in supplementary data $3 \mathrm{~B}$, diapauses hormone precursor gene was expressed only in starved larvae at V5N and V13N.

Besides these two proteins, the glutathione S-transferase 10 was identified at V5 but not found from V4N to V13N (Figure 4(c)). The expressions of a PDI-like protein ERp57 and a vacuolar ATPase B subunit were upregulated at V6N and thereafter downregulated and returned to the same level as feeding silkworm (Figure 4(d)). The amounts of $\mathrm{H}+$-transporting ATP synthase beta subunit isoform 2 and imaginal disc growth factor were at first lower in nonfeeding larvae but finally increased to the same level as in feeding larvae (Figures 4(d) and 4(e)). In Figure 4(f), we found that the amount of an abnormal wing disc-like protein decreased with development progress in feeding larvae, but after starvation, it kept a stable level (Figure 4(g)).

\section{Discussion}

The domesticated silkworm, Bombyx mori, is a herbivorous insect and a model organism for Lepidoptera. Chinese and Japanese scientists made great efforts to accomplish the sequencing project of the whole silkworm genome $[17,18]$, which offers Bombyx researchers an opportunity to identify peptides using proteomic method. Midgut, the largest digestive organ in the silkworm body, is important for the proteomic research $[10,11]$. Besides cuticle, silkworm midgut is another large interface between intra and extra. It is an entry for pathogens, toxins, and pesticides. Hence, any knowledge of protein components of silkworm midgut would be essential for developing new lepidopteran pest control strategies.

In this study, we used two-dimensional electrophoresis combined with MALDI-TOF-MS to analyse the midgut proteins in the normal fifth-instar silkworm larvae as well 

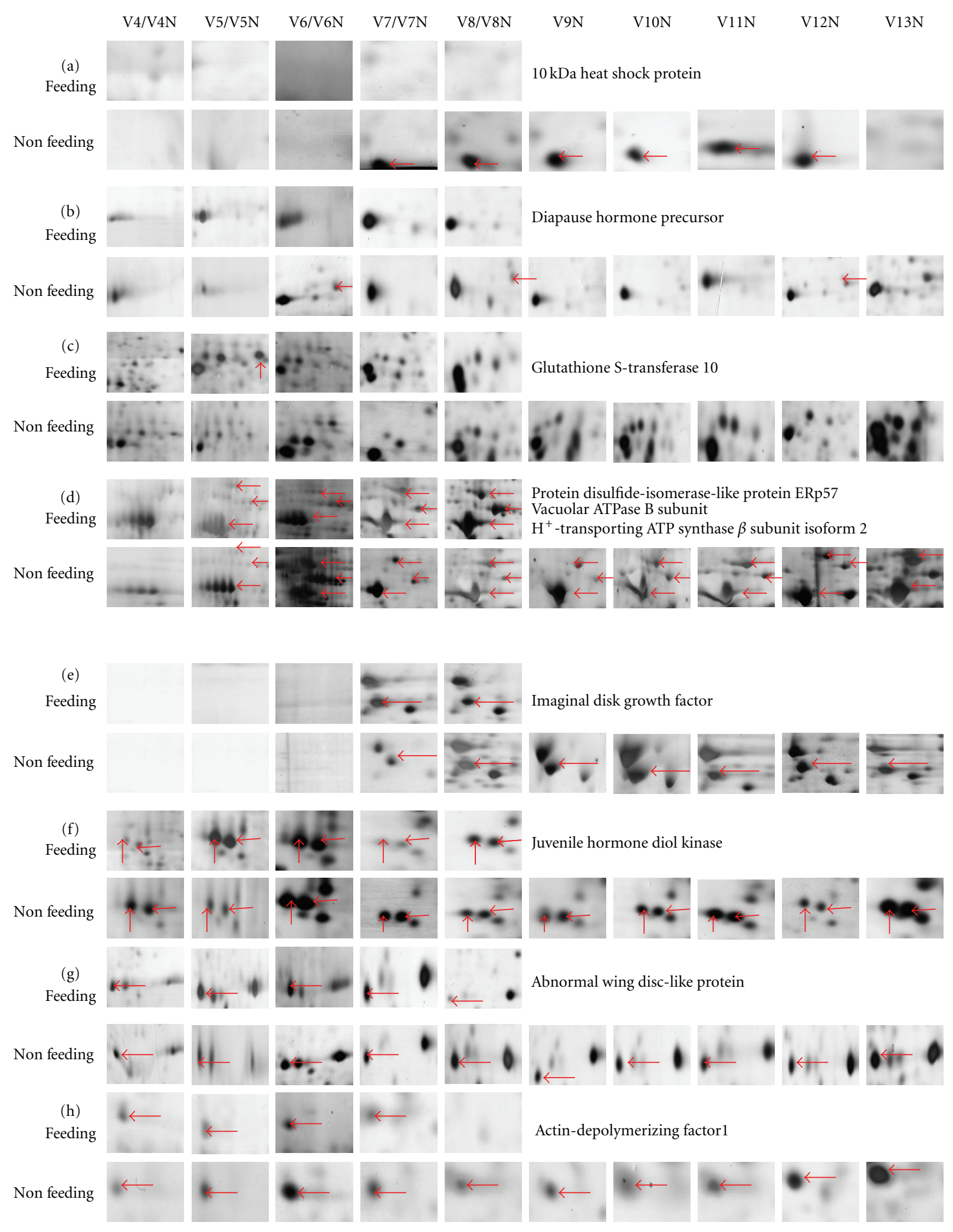

FIGURE 4: The partial enlargement of the midgut proteins in nonfeeding silkworms. Red arrows pointed out the target proteins and their names were displayed at right. Vx means fifth-instar day-x larvae. 
as in the starved larvae. The numbers of proteins in two groups were gradually increased from day 3 to the last larval day, suggesting that more and more midgut proteins may participate in the growth and metamorphosis of this tissue. Of the 96 proteins identified in this proteomics analysis, 69 proteins had not been observed prior to this study $[10,11$, $15,16]$, and the majority of midgut proteins detected showed developmental differences. For example, JHDK is responsible for the degradation of $\mathrm{JH}$. Li et al. found that the mRNA of JHDK was expressed throughout 4th- and 5th-instar larvae at a constant level and distributed in foregut and midgut [19]. While JHDK protein reaches its peak at day 6 of 5thinstar larvae, it seems likely that it might be responsible for the decreased titer of $\mathrm{JH}$ at that stage. The fatty-acid-binding protein is involved in fatty acid transport. According to the microarray data, the gene for fatty-acid-binding protein was expressed in the 5th-instar silkworm larvae with a higher level at days 4-5, and then decreased to a constant level. The highest abundance of this protein was observed at day 6 on our 2-DE profiles, suggesting the active metabolism of lipids at that time. The abnormal wing disc-like protein detected was dramatically decreased at the day 8 . It has the nucleoside diphosphate kinase activity and is involved in epithelial integrity [20]. Our observation indicated that it was regulated by hormone. Our analysis also led us to find a transferrin. Transferrin is a multifunction protein working in iron binding, transportation, cell growth, differentiation, and protection cells by inhibiting apoptosis [21].

Different insects have different responses to starvation. In some insects like Manduca sexta, the subsequent development of their larvae would be delayed when starved [22], but Onthophagus taurus larvae respond to food deprivation by shortening the length of the instar, becoming premature, pupating, and eclosing early to be small adults [23]. Bombyx mori belongs to the former type. When the 5th-instar silkworm larvae are starved from day 3 , the duration of larval stage would be prolonged. It was found that the threshold weight is needed before metamorphosis in Psacothea hilaris [24]. This may be a reason why most of starved silkworm larvae were unable to pupate.

Our data showed that nine proteins undetectable in feeding larvae before metamorphosis were still detected in nonfeeding silkworm. Of these proteins, actin-depolymerizing factor 1 plays roles in regulating F-actin organization, in cell and organ expansion [25]. More detailed analysis will uncover its function in silkworm midgut. Proteomic analysis also allowed us to identify two proteins only existing in the midgut of the starved silkworm larvae. One is a small heat shock protein and the other is a diapause hormone precursor. Small heat shock proteins are known to act as molecular chaperones to refold polypeptides trapped in protein aggregates and to degrade the misfolded proteins [26]. It has been reported that small heat shock protein has additional functions such as the regulation of programmed cell death and the promotion or inhibition of apoptosis to maintain homeostasis [27-31]. This small heat shock protein was undetectable in normal feeding larvae but can be detected in starvation ones, suggesting that it may play some roles in starved larvae for survival. Diapause hormone precursor which is relative to the synthesis of diapause hormone is another protein identified in the starved larvae. Insects can undergo diapause under extreme conditions. Gene encoding diapause hormone precursor is expressed by the induction of starvation, suggesting that, when confronts starvation, larva would stop its development against starvation for survival.

Interestingly, the starved larvae produced more JHDK than the normal feeding ones. The more JHDK, the lower $\mathrm{JH}$ titer. At the end of penultimate instar of larva, metamorphosis is characterized by a sharp decrease in JH. However, most of the starved larvae did not undergo metamorphosis, indicating that low level of $\mathrm{JH}$ titer associated with high level of ecdysteroid titer in nutrition state is essential for initiating larval-to-pupal metamorphosis.

Larval midgut is a main place where digestion action usually occurs due to digestive enzymes. In this study, we found that, in starvation situation, the digestive enzymes in larvae midgut were not disappeared. These digested enzymes such as glycosidase, amylase, and trehalase were synthesized, secreted, and trapped into the glycocalyx, as first proposed by Santos et al. [32].

Since the chemical pesticides cause serious environmental problems, new strategies for pest control need to be developed. So far, there have been two major methods for pests control via insect midgut [33]. One is to use Cry toxins from $B$. thuringiensis as biocontrol agents to lyse midgut epithelial. Another is to use RNAi technology. Selected RNAi targets in the midgut include mRNAs coding for vacuolar ATPase, ribosomal protein S4, actin, and $\alpha$-tubulin [33]. Our present study provided more targets derived from midgut for the pest management.

\section{Acknowledgments}

This work was supported by Research Grants from the National Science Foundation of China (no. 30871825), the National Hi-Tech Research and Development Program of China (no. 2006AA10A118), and the Doctorial Innovation Fund (no. kb2009002) of the Southwest University. The authors appreciate the helpful comments of three reviewers on an earlier version of this paper.

\section{References}

[1] M. R. Goldsmith and F. Marec, Molecular Biology and the Genetics of the Lepidoptera, Contemporary Topics in Entomology Series, CRC Press, Boca Raton, Fla, USA, 2010.

[2] G. Cermenati, P. Corti, S. Caccia et al., "A morphological and functional characterization of Bombyx mori larval midgut cells in culture," Invert Surv J., vol. 4, no. 2, pp. 119-126, 2007.

[3] W. R. Terra and C. Ferreira, "Biochemistry of digestion," in Comprehensive molecular insect science, vol. 4, pp. 171-224, Elsevier, Oxford, UK, 2005.

[4] C. D. Santos, A. F. Ribeiro, C. Ferreira, and W. R. Terra, "The larval midgut of the cassava hornworm (Erinnyis ello)Ultrastructure, fluid fluxes and the secretory activity in relation to the organization of digestion," Cell and Tissue Research, vol. 237, no. 3, pp. 565-574, 1984. 
[5] G. F. Martins, C. A. Neves, L. A. O. Campos, and J. E. Serrão, "The regenerative cells during the metamorphosis in the midgut of bees," Micron, vol. 37, no. 2, pp. 161-168, 2006.

[6] H. Nakazawa, E. Tsuneishi, K. M. Ponnuvel et al., "Antiviral activity of a serine protease from the digestive juice of Bombyx mori larvae against nucleopolyhedrovirus," Virology, vol. 321, no. 1, pp. 154-162, 2004.

[7] K. M. Ponnuvel, H. Nakazawa, S. Furukawa et al., "A lipase isolated from the silkworm Bombyx mori shows antiviral activity against nucleopolyhedrovirus," Journal of Virology, vol. 77, no. 19, pp. 10725-10729, 2003.

[8] A. Bravo, S. S. Gill, and M. Soberón, "Mode of action of Bacillus thuringiensis Cry and Cyt toxins and their potential for insect control," Toxicon, vol. 49, no. 4, pp. 423-435, 2007.

[9] J. A. Baum, T. Bogaert, W. Clinton et al., "Control of coleopteran insect pests through RNA interference," Nature Biotechnology, vol. 25, no. 11, pp. 1322-1326, 2007.

[10] H. P. Yao, X. W. Xiang, L. Chen et al., "Identification of the proteome of the midgut of silkworm, Bombyx mori L., by multidimensional liquid chromatography (MDLC) LTQOrbitrap MS," Bioscience reports, vol. 29, no. 6, pp. 363-373, 2009.

[11] H. Kajiwara, Y. Ito, A. Imamaki, M. Nakamura et al., "Protein profile of silkworm midgut of fifth-instar day-3 larvae," Electrophoresis, vol. 49, no. 2, pp. 61-69, 2005.

[12] Y. Li, K. Chen, Q. Yao et al., "The effect of calorie restriction on growth and development in silkworm, Bombyx mori," Archives of Insect Biochemistry and Physiology, vol. 71, no. 3, pp. 159172, 2009.

[13] S. Satake, Y. Kawabe, and A. Mizoguchi, "Carbohydrate metabolism during starvation in the silkworm Bombyx mori," Archives of Insect Biochemistry and Physiology, vol. 44, no. 2, pp. 90-98, 2000.

[14] Y. Hou, Q. Xia, P. Zhao et al., "Studies on middle and posterior silk glands of silkworm (Bombyx mori) using two-dimensional electrophoresis and mass spectrometry," Insect Biochemistry and Molecular Biology, vol. 37, no. 5, pp. 486-496, 2007.

[15] H. Yao, A. Guo, F. He, X. Lu, and X. Wu, "Proteomics of midgut of fifth-instar silkworm larva," Chinese Journal of Biotechnology, vol. 24, no. 1, pp. 89-94, 2008.

[16] Y. Hou, J. Guan, P. Zhao et al., "Proteomics analysis of midgut from silkworm, Bombyx mori," Science of Sericulture, vol. 33, no. 2, pp. 216-222, 2007.

[17] Q. Xia, Z. Zhou, C. Lu et al., "A draft sequence for the genome of the domesticated silkworm (Bombyx mori)," Science, vol. 306, no. 5703, pp. 1937-1940, 2004.

[18] K. Mita, M. Kasahara, S. Sasaki et al., "The genome sequence of silkworm, Bombyx mori," DNA Research, vol. 11, no. 1, pp. 27-35, 2004.

[19] S. Li, Q. R. Zhang, W. H. Xu, and D. A. Schooley, "Juvenile hormone diol kinase, a calcium-binding protein with kinase activity, from the silkworm, Bombyx mori," Insect Biochemistry and Molecular Biology, vol. 35, no. 11, pp. 1235-1248, 2005.

[20] J. A. Woolworth, G. Nallamothu, and T. Hsu, "The Drosophila metastasis suppressor gene Nm23 homolog, awd, regulates epithelial integrity during oogenesis," Molecular and Cellular Biology, vol. 29, no. 17, pp. 4679-4690, 2009.

[21] P. T. Gomme and K. B. McCann, "Transferrin: structure, function and potential therapeutic actions," Drug Discovery Today, vol. 10, no. 4, pp. 267-273, 2005.

[22] H. F. Nijhout, "A threshold size for metamorphosis in the tobacco hornworm, Manduca sexta (L.)," Biological Bulletin, vol. 149, no. 1, pp. 214-225, 1975.
[23] M. Shafiei, A. P. Moczek, and H. F. Nijhout, "Food availability controls the onset of metamorphosis in the dung beetle Onthophagus taurus (Coleoptera: Scarabaeidae)," Physiological Entomology, vol. 26, no. 2, pp. 173-180, 2001.

[24] F. N. Munyiri, W. Asano, Y. Shintani, and Y. Ishikawa, "Threshold weight for starvation-triggered metamorphosis in the yellow-spotted longicorn beetle, Psacothea hilaris (Coleoptera: Cerambycidae)," Applied Entomology and Zoology, vol. 38, no. 4, pp. 509-515, 2003.

[25] C. H. Dong, G. X. Xia, Y. Hong, S. Ramachandran, B. Kost, and N. H. Chua, "ADF proteins are involved in the control of flowering and regulate f-actin organization, cell expansion, and organ growth in arabidopsis," Plant Cell, vol. 13, no. 6, pp. 1333-1346, 2001.

[26] J. P. Hendrick and F.-U. Hartl, "The role of molecular chaperones in protein folding," FASEB Journal, vol. 9, no. 15, pp. 1559-1569, 1995.

[27] C. Y. Li, J. S. Lee, Y. G. Ko, J. I. Kim, and J. S. Seo, "Heat shock protein 70 inhibits apoptosis downstream of cytochrome c release and upstream of caspase- 3 activation," Journal of Biological Chemistry, vol. 275, no. 33, pp. 25665-25671, 2000.

[28] D. D. Mosser, A. W. Caron, L. Bourget, C. Denis-Larose, and B. Massie, "Role of the human heat shock protein hsp70 in protection against stress-induced apoptosis," Molecular and Cellular Biology, vol. 17, no. 9, pp. 5317-5327, 1997.

[29] S. R. Kirchhoff, S. Gupta, and A. A. Knowlton, "Cytosolic heat shock protein 60, apoptosis, and myocardial injury," Circulation, vol. 105, no. 24, pp. 2899-2904, 2002.

[30] S. Xanthoudakis, R. Sophie, D. Rasper et al., "Hsp60 accelerates the maturation of pro-caspase- 3 by upstream activator proteases during apoptosis," EMBO Journal, vol. 18, no. 8, pp. 2049-2056, 1999.

[31] R. Ran, A. Lu, L. Zhang et al., "Hsp70 promotes TNFmediated apoptosis by binding IKK $\gamma$ and impairing NF- $\kappa \mathrm{B}$ survival signaling," Genes and Development, vol. 18, no. 12, pp. 1466-1481, 2004.

[32] C. D. Santos, A. F. Ribeiro, and W. R. Terra, "Differential centrifugation, calcium precipitation, and ultrasonic disruption of midgut cells of Erinnyis ello caterpillars. Purification of cell microvilli and inferences concerning secretary mechanisms," Canadian Journal of Zoology, vol. 64, no. 2, pp. 490-500, 1986.

[33] R. S. Hakim, K. Baldwin, and G. Smagghe, "Regulation of midgut growth, development, and metamorphosis," Annual Review of Entomology, vol. 55, pp. 593-608, 2010. 

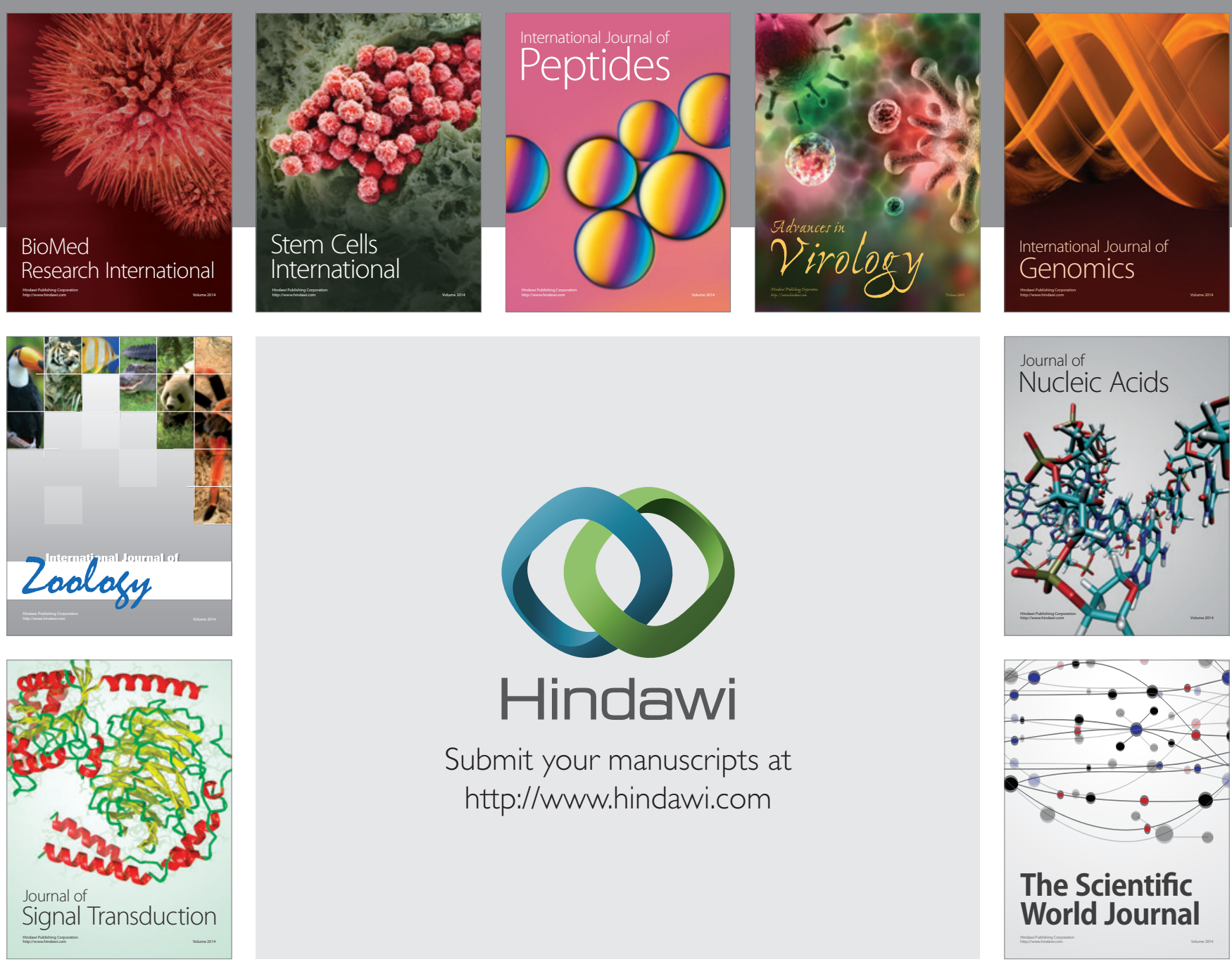

Submit your manuscripts at

http://www.hindawi.com
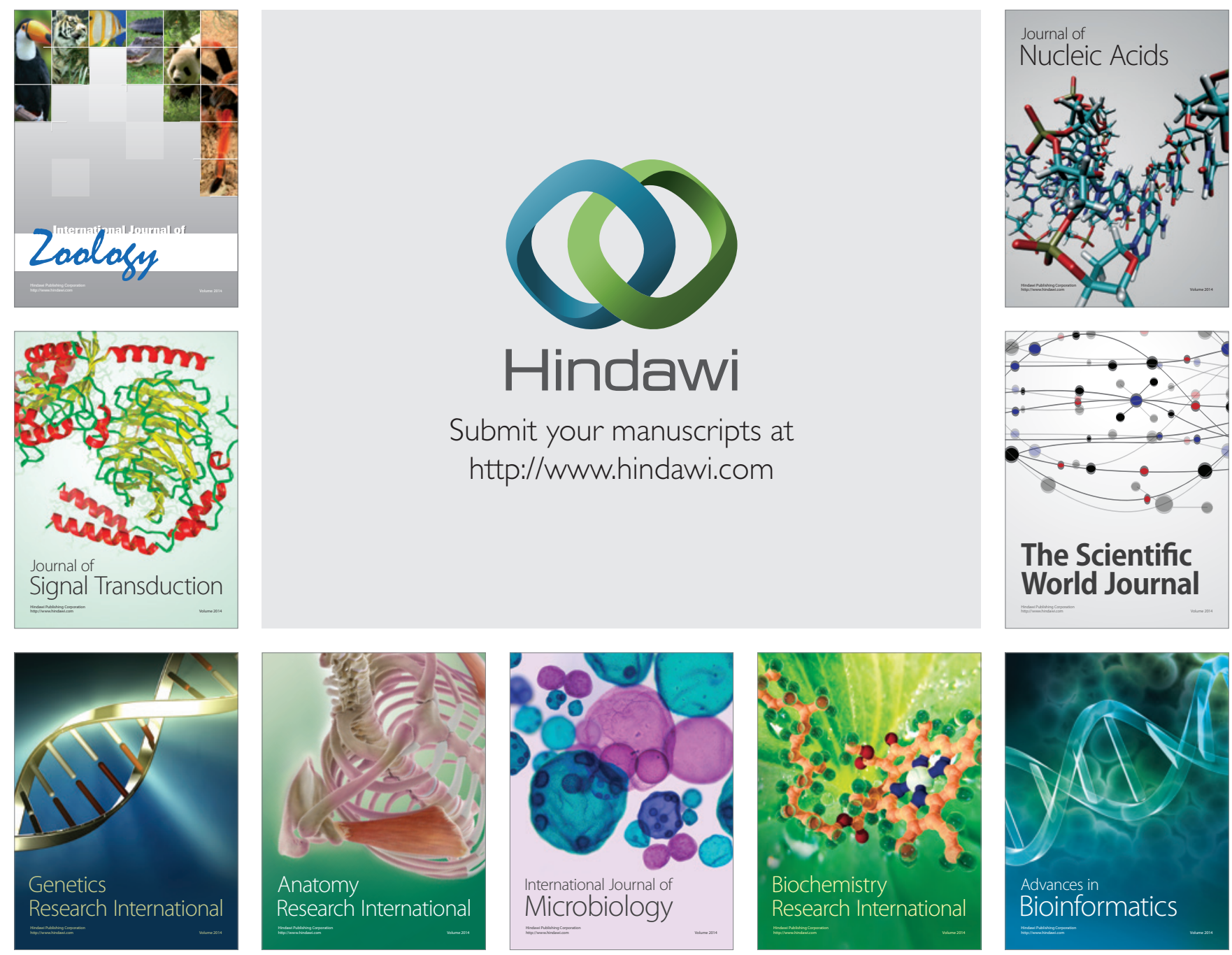

The Scientific World Journal
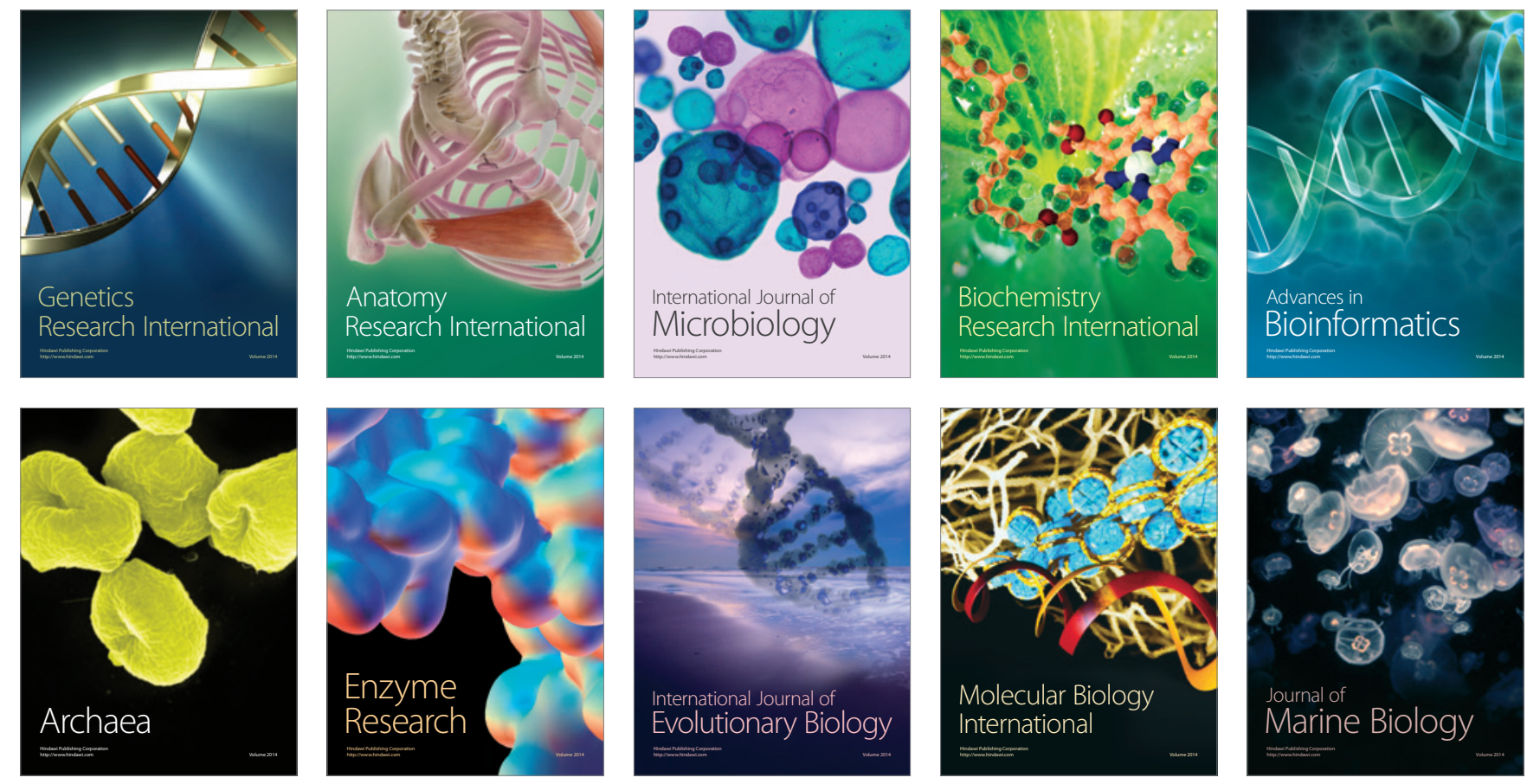